\title{
RESENHA: Um panorama do cenário brasileiro sobre atendimento psicológico em clínicas-escola
}

\author{
Fabiana Vieira Gauy \\ Luan Flávia Barufi Fernandes \\ Universidade de São Paulo, São Paulo-SP, Brasil
}

Silvares, E. F. M. (Org.). (2006). Atendimento psicológico em clínicas-escola. Campinas, SP: Átomo.

Atualmente, o ensino e formação em Psicologia têm recebido atenção especial pelo Conselho Federal de Psicologia e pelas instituições formadoras, no sentido de ampliar o repertório de atuação do psicólogo para atender de forma satisfatória as necessidades da população brasileira. Um caminho essencial para fundamentar e refletir sobre este tema é investigar como as clínicas-escola de Psicologia têm contribuído para a formação dos psicólogos no Brasil. A presente obra tem por objetivo apresentar uma panorama do cenário brasileiro de como estas instituições estão oferecendo atendimento psicológico à comunidade.

A clínica-escola em Psicologia consiste no ambiente associado a uma instituição de ensino, no qual o aluno completa a sua formação ao realizar a prática clínica, sob a orientação de um professorsupervisor. Esta tem o objetivo de promover ações e procedimentos que possibilitem o ensino e a pesquisa, contribuindo para a formação do aluno, ao mesmo tempo em que ele atende à comunidade. Apesar de fazer parte da formação de todos os psicólogos clínicos, o tema clínica-escola na Psicologia ainda tem recebido pouca atenção.

O referente livro enfoca este tema ao compartilhar com os leitores as reflexões decorrentes dos encontros, relativos a esta temática, realizados em congressos da Associação Nacional de Pesquisa e Pós-Graduação em Psicologia (ANPEPP). Estes encontros visam ampliar as discussões sobre a atuação e funcionamento das clínicas-escolas brasileiras de Psicologia a partir do reconhecimento da prática e pesquisa clínica, do perfil da demanda, da dinâmica de diferentes serviços e das necessidades de mudan- ças para melhor atender aos objetivos de um serviçoescola. Assim, esta obra contribui de forma teórica e prática ao abordar aspectos metodológicos e conceituais do atendimento e da pesquisa clínico-institucional e ao apresentar modelos de serviços de atendimento psicológico a diferentes clientelas.

O livro foi dividido em quatro partes. Inicialmente, no Capítulo 1, há uma preocupação de se esclarecer alguns aspectos metodológicos e teóricos. São abordadas questões históricas e conceituais das clínicas-escola, previstas na legislação pelo parecer 403/62, que criou a profissão e que pela lei 4119/62 foi regulamentada; discussões dos entraves logísticos destes serviços devido à alta demanda e à proposta de atendimento pautada no modelo individual semelhante ao modelo médico, condição geradora de longas filas de espera, resultando em altos índices de desistência; e reflexões sobre a necessidade do uso de novos procedimentos para melhor atender o binômio: formação acadêmica e atendimento à comunidade.

Já no Capítulo 2, discute-se metodologia de pesquisa em intervenções clínicas institucionais. $\mathrm{O}$ objetivo foi apresentar alguns desafios a serem superados na pesquisa clínica, e sugestões de indicações metodológicas para pesquisa nesta área: delineamentos não experimentais e experimentais, de sujeito único e de grupo. Sugerem-se oito considerações relevantes em pesquisa clínica, a saber: (1) pergunta, (2) delineamento, (3) coleta de dados, (4) ética, (5) análise de dados, (6) formas de obter concordância e treinar juízes, (7) tratamento dos dados, e (8) limites das conclusões.

No Capítulo 3, apresenta-se o Programa PsicoUSP, utilizado na clínica-escola do Departamento de Psicologia Clínica do Instituto de Psicologia da Uni- 
versidade de São Paulo (USP). Este é um programa de gerenciamento de fluxo de cliente e de profissionais que prestam atendimento à referida clínica-escola. O uso desta ferramenta possibilita a criação de um banco de dados facilmente acessado pelo clínico, pelo supervisor e pela equipe gerencial do serviço, contribuindo para sua melhor organização, para o estabelecimento de metas e decisões que facilitem seu gerenciamento e para a realização de diversas pesquisas.

Esta parte inicial termina com o Capítulo 4, que defende o levantamento do perfil da clientela atendida como o primeiro passo para que o atendimento oferecido seja satisfatório e eficiente. As autoras deste capítulo introduzem o tema descrevendo estudos nacionais e internacionais que apontam que o perfil dos clientes de clínica-escola é caracterizado por indivíduos do sexo masculino, em idade escolar (seis a dez anos), com queixa de problemas de aprendizagem e problemas externalizantes, encaminhados pela escola. Em seguida, apresentam um levantamento realizado em cinco instituições, três da região sudeste (São Paulo, Ribeirão Preto e Rio de Janeiro), uma do centro-oeste (Goiânia) e uma do sul (Curitiba) a partir dos dados do Child Behavior Checklist 4-18 anos, exemplificando como é necessário e possível formar o aluno e ao mesmo tempo atender às demandas da comunidade de forma eficiente e eficaz, quando se faz um mapeamento de quem, como, por quem, e por quê se atende.

A partir da segunda parte, o livroé dividido por atendimento às crianças, aos adolescentes e aos adultos. Na segunda parte, o Capítulo 5 descreve o atendimento do Grupo de Pesquisa em Problemas de Aprendizagem, Desenvolvimento e Saúde Mental do Escolar da Faculdade de Medicina de Ribeirão Preto da Universidade de São Paulo (USP), com crianças de seis a sete anos (meninice), com dificuldades escolares, a partir da avaliação da trajetória do curso do desenvolvimento por dois estudos prospectivos com crianças que apresentaram dificuldades escolares precoces.

O Capítulo 6 apresenta uma forma alternativa de atendimento psicológico a partir da descrição de dois grupos de espera criado na clínica-escola da USP; um para diminuir a taxa de evasão e o outro para aquelas crianças que esperavam enquanto os pais recebiam orientação. Além destes objetivos primários, os dois grupos também auxiliam a avaliação diagnóstica dos casos atendidos e proporcionam dados descritivos sobre a demanda e estratégias para diminuição da evasão/desistência. Esta parte é finalizada com o Capítulo 7, que discute a formação do psicólogo no atendimento à criança, no contexto hospitalar dos serviços de pediatria, e descreve o funcionamento e atendimento oferecido pelo Setor de Psicologia do Desenvolvimento do Departamento de Fonoaudiologia da Universidade Federal de São Paulo (UNIFESP).

A terceira parte do livro se refere ao atendimento psicológico a adolescentes em clínicas-escola. No Capítulo 8, apresenta-se a descrição e modo de funcionamento do Centro de Atendimento e Apoio ao Adolescente (CAAA) do Departamento de Pediatria da UNIFESP. Há a atuação de uma equipe multidisciplinar que procura identificar grupos de risco, detectar precocemente problemas, propor tratamento adequado e integral, bom como desenvolver trabalho preventivo. A Psicologia intervém junto aos adolescentes em formato grupal com enfoque preventivo e curativo de problemas no período da adolescência. É descrita uma abordagem diferenciada e integrada de atuação da Psicologia junto a esta população específica.

No Capítulo 9, relata-se a implantação de um programa de clínica-escola de Psicologia para atender usuários de substâncias psicoativas. Apresentamse dados epidemiológicos sobre adolescentes usuários de drogas em Porto Alegre-RS, que foram encaminhados pelo Ministério Público ao Laboratório de Intervenções Cognitivas (LABICO) da Pontifícia Universidade Católica do Rio Grande do Sul (PUCRS). Este estudo apontou a necessidade de um trabalho inicial que aumente adesão desta clientela, que desafia terapeutas, principalmente, aquela que vem por mandato judicial pela ausência de motivação.

A última divisão do livro apresenta reflexões clínicas e exemplos de intervenções psicoterápicas 
voltadas para o atendimento de adultos em clínicasescola. O Capítulo 10 procura investigar e aumentar a compreensão da resistência do paciente e dos aspectos da relação terapêutica que favorecem ou dificultam a mudança. Há a descrição de uma pesquisa que teve como objetivo investigar como os terapeutas cognitivo-comportamentais reagem à resistência de “pacientes difíceis". Participaram deste estudo 58 terapeutas, que responderam a um questionário contendo 17 situações terapêuticas típicas de resistência. A maioria dos terapeutas revelou experimentar sentimentos negativos frente aos comportamentos de resistência do paciente. Segundo relato coletado, o impacto na relação terapêutica e no terapeuta foi menor, quanto maior era sua experiência clínica.

São apresentados no Capítulo 11 modelos de tratamentos em grupo de transtornos psiquiátricos (Transtorno do Pânico e Agorafobia, Fobia Social e Depressão) implantados pela Divisão de Psicologia Aplicada do Instituto de Psicologia da Universidade Federal do Rio de Janeiro (UFRJ). São descritos métodos, estrutura das sessões e os resultados obtidos de cada tratamento relatado.

Já no Capítulo 12, propõe-se uma intervenção em grupo informativo, com orientação psicoterapêutica, para mulheres no período da menopausa. Relata-se um estudo realizado com 44 mulheres, que participaram dessa intervenção, e que tiveram como comportamentos de interesse sintomas típicos dessa fase: dificuldades de sono, variação de humor, ansiedade e depressão. Os resultados indicaram tendência à diminuição dos escores relativos a estes sintomas. A estrutura das sessões dos grupos é descrita detalhadamente, condição que facilita a replicação da intervenção e aborda tema de importância para a saúde pública devido ao aumento da expectativa de vida da população.

O livro é finalizado com a relevante discussão sobre o abandono de psicoterapia em clínicas-escola. Os autores sinalizam que esta taxa pode ser um índice seguro para medir a eficiência de uma terapia ou serviço de atendimento, que a falta de aliança terapêutica é o fator mais associado e que o abandono do paciente tem impacto tanto financeiro, como pedagó- gico, uma vez que pode atingir a auto-imagem e autoestima do aluno-estagiário. Apresenta-se um estudo retrospectivo correlacional, obtido através de protocolos de pacientes que fizeram psicoterapia individual na Clínica Psicológica da Universidade Católica de Pelotas (UCEPel). Observou-se que a probabilidade de abandono é maior entre os adultos jovens e entre os que fizeram menos de 15 sessões, principalmente se houve troca de terapeutas.

Esta obra apresenta um panorama amplo e diverso do funcionamento de algumas clínicas-escola de Psicologia no Brasil e descreve intervenções psicológicas para diferentes problemáticas que são realizados nestas instituições, facilitando a reprodução dos tratamentos e propondo novas alternativas de atendimento em Psicologia Clínica. Ressalta-se que as clínicas-escola participantes deste livro, se localizam nas regiões Sudeste e Sul do Brasil, impedindo a generalização das informações no âmbito nacional, pois não há a inclusão de dados de outras regiões brasileiras. Sugere-se que em uma próxima edição ou volume, estas regiões sejam contempladas a fim de enriquecer o panorama desta temática.

O livro em questão tem como foco o atendimento psicológico em clínicas-escola e tem a proposta de instrumentalizar clínicos iniciantes, estagiários, supervisores e profissionais, colaborando para estimular a reflexão sobre a prática clínica e dando destaque para a avaliação contínua dos serviços oferecidos e adequação destes às demandas de sua clientela. Considera-se que a presente obra atende ao que se propõe de forma satisfatória, porém, deve ser considerada como o primeiro passo para a discussão de como concretizar sistematicamente os objetivos das clínicas-escola, a saber: ensino, pesquisa e extensão de serviços à comunidade, pois as demandas de atendimento psicológico da população brasileira são diversas e singulares, exigindo do psicólogo um repertório amplo de intervenções, condição que a psicoterapia individual não mais satisfaz. Além disso, o ensino, pesquisa e implementação de formas alternativas e adequadas às reais necessidades da clientela, são de extrema relevância e importância para o futuro da Psicologia no Brasil. 
Resenha recebida em 25/03/2008.

Aceita para publicação em 27/06/2008.

Endereço para correspondência:

Luan Flávia Barufi Fernandes. Departamento de Psicologia Clínica. Instituto de Psicologia da Universidade de São Paulo. Avenida Professor Lúcio Martins Rodrigues, nº1721, Bloco D, Sala 30, São Paulo-SP. E-mail: luanflavia@hotmail.com

Fabiana Vieira Gauy é doutoranda pelo Programa de Pós-graduação em Psicologia do Instituto de Psicologia da Universidade de São Paulo.

Luan Flávia Barufi Fernandes é mestranda pelo Programa de Pós-graduação em Psicologia do Instituto de Psicologia da Universidade de São Paulo. 